\title{
Louis Lobbes, Des "Apophtegmes" à la "Polyanthée". Érasme et le genre des dits mémorables
}

\section{Michele Mastroianni}

\section{(2) OpenEdition}

1 Journals

\section{Edizione digitale}

URL: http://journals.openedition.org/studifrancesi/389

DOI: 10.4000/studifrancesi.389

ISSN: 2421-5856

\section{Editore}

Rosenberg \& Sellier

\section{Edizione cartacea}

Data di pubblicazione: 1 aprile 2015

Paginazione: 133-134

ISSN: 0039-2944

\section{Notizia bibliografica digitale}

Michele Mastroianni, « Louis Lobbes, Des "Apophtegmes" à la "Polyanthée". Érasme et le genre des dits mémorables », Studi Francesi [Online], 175 (LIX | I) | 2015, online dal 01 avril 2015, consultato il 18 septembre 2020. URL : http://journals.openedition.org/studifrancesi/389; DOI : https://doi.org/ 10.4000/studifrancesi.389

Questo documento è stato generato automaticamente il 18 settembre 2020.

\section{(c) $(1) \ominus$}

Studi Francesi è distribuita con Licenza Creative Commons Attribuzione - Non commerciale - Non opere derivate 4.0 Internazionale. 


\title{
Louis Lobbes, Des "Apophtegmes" à la "Polyanthée". Érasme et le genre des dits mémorables
}

\author{
Michele Mastroianni
}

\section{NOTIZIA}

LOUIS LOBBES, Des “Apophtegmes" à la "Polyanthée". Érasme et le genre des dits mémorables, Paris, Champion, 2013 («Textes Littéraires de la Renaissance», 12), pp. 2000 (3 voll.).

1 Gli Apophtegmata di Erasmo (1 ${ }^{\text {a }}$ ed. 1531 in sei libri, $2^{\text {a }}$ ed. 1532 in otto libri), raccolta di oltre tremila "dits mémorables», furono, come ben sottolinea L. Lobbes, opera fortunatissima nel Cinquecento (una novantina di edizioni, dodici traduzioni in quattro lingue diverse, vari adattamenti, di cui due in versi), saccheggiata e copiata da Conrad Lycosthenes nei suoi Apophtegmata, riassorbita in parte dalle edizioni del secondo Cinquecento della Polyanthea di Domenico Nani Mirabelli, enciclopedia quest'ultima di straordinaria diffusione. Tuttavia, forse proprio a causa di questo riutilizzo - e di una critica che vedeva in quest'opera solo una pallida eco degli Adagia - sono mancate non solo edizioni critiche ma anche moderne degli Apophtegmata. Ora, questo vuoto editoriale è colmato dalla monumentale edizione critica a cura di L. Lobbes, che fornisce il testo latino tenendo conto delle stampe del 1531, 1532 e 1535. A fronte del testo latino di Erasmo vengono pubblicate la traduzione francese di Antoine Macault (dei libri I-V pubblicata nel 1539, condotta con buona probabilità sulla seconda stampa del 1532) e quella di un ignoto continuatore (dei libri VI-VIII pubblicata nel 1553). Viene inoltre offerta la rielaborazione in versi, ad opera di Guillaume Haudent, di una parte degli Apophtegmata (Les Faitz et gestes memorables de plusieurs gens remplis d'une admirable doctrine et condition [...], Lyon, 1557) e la traduzione in versi ad opera di Gabriel Pot (Les deux premiers Livres [...], e Suitte des troisieme et quatrieme Livres [...], Lyon, 1574). Questo corpus imponente è accompagnato da commentaires minuziosi che indicano la fonte di ogni apophtegma, segnalando le varianti della versione latina di Erasmo rispetto 
all'originale greco. Strumenti utili di ricerca sono un Tableau de concordances ove la numerazione della presente edizione viene raffrontata a quella delle edizioni del 1531, 1532 e 1535, e a quella delle traduzioni francesi di Macault e del continuatore; un Lexique accurato dei testi francesi; un Index personarum; e soprattutto un Index sententiarum che permette agli editori di testi debitori degli Apophtegmata di muoversi agevolmente nella selva di citazioni. Inoltre l'ampia monografia, che costituisce l'introduzione (pp. 13-160), non solo illustra la struttura («Le découplage en livres», pp. 59-92) dell'opera erasmiana, ma affrontando il problema del ruolo rivestito in Erasmo dalla forma breve, sottolinea i rapporti istituiti dal grande umanista con l'opera di Plutarco, i cui testi forniscono un materiale di primaria importanza per la frammentazione in massime operata dagli Apophtegmata. 